\title{
Clinical trial design of serious gaming in mild cognitive impairment
}

\author{
Cristina Muscio ${ }^{1,2 *}$, Pietro Tiraboschi ${ }^{3}$, Ugo P. Guerra ${ }^{4}$, Carlo A. Defanti ${ }^{1}$ and \\ Giovanni B. Frisoni ${ }^{5,6}$
}

${ }^{1}$ Fondazione Europea Ricerca Biomedica, Centro Eccellenza Alzheimer, Ospedale Briolini, Bergamo, Italy, ${ }^{2}$ Department of Molecular and Translational Medicine, University of Brescia, Brescia, Italy, ${ }^{3}$ Division of Neurology V/Neuropathology, Fondazione IRCCS Istituto Neurologico "Carlo Besta", Milan, Italy, ${ }^{4}$ Fondazione Poliambulanza, Nuclear Medicine Department, Brescia, Italy, ${ }^{5}$ Laboratory of Epidemiology, Neuroimaging and Telemedicine, IRCCS Centro San Giovanni di Dio-Fatebenefratelli, Brescia, Italy, ${ }^{6}$ Memory Clinic and LANVIE - Laboratory of Neuroimaging of Aging, University Hospitals and University of Geneva, Geneva, Switzerland

Keywords: serious games, Alzheimer's disease, mild cognitive impairment, biomarker enrichment strategy, outcome measures, clinical trials

\section{OPEN ACCESS}

Edited by: Philippe Robert, University of Nice Sophia Antipolis, France

Reviewed by:

Alexandra König,

EA CoBTek CHU de Nice - Université de Nice Sophia Antipolis, France Julian Alvarez,

Lille1 University, France

Francois Bremond, Inria, France

*Correspondence: Cristina Muscio, cristina.muscio@gmail.com

Received: 18 January 2015 Accepted: 23 February 2015 Published: 11 March 2015

Citation:

Muscio C, Tiraboschi P, Guerra UP, Defanti CA and Frisoni GB (2015) Clinical trial design of serious gaming in mild cognitive impairment.

Front. Aging Neurosci. 7:26. doi: 10.3389/fnagi.2015.00026

\section{Introduction}

The “Global Impact of Dementia: 2013-2050” (Alzheimer’s Disease International, 2013), released ahead of the December 2013 G8 Dementia Summit in London, estimated that 44.35 million people in the world were living with dementia in 2013. This number was predicted to increase to 75.6 million in 2030, and 135.5 million in 2050. This dramatic increase will have profound implications for social and economic costs (Alzheimer's Disease International, 2010). Since the most common dementia subtype (50-75\%) is Alzheimer's disease (AD), its early detection and clinical effectiveness of its prevention and treatment represent a major public health concern and have been identified as a research priority (Alzheimer's Disease International, 2009; Ballard et al., 2011; Foster et al., 2014).

Recently, there has been a growing interest in employing Information and Communication Technologies (ICT) to evaluate patient's cognitive and functional impairment for early detection of AD (Wan Shamsuddin et al., 2011; Tarnanas et al., 2014). Beyond being important for assessment, ICT can also play a key role in the patient's treatment, stimulation, and rehabilitation (Robert et al., 2014). This is the idea underlying the current use of Serious Games (SGs), which are a broader reapplication of videogames resources integrating gaming and serious purposes. Lately, a few studies have started to investigate the efficacy of SGs used as an ICT intervention, which target cognitive decline, in people with $\mathrm{AD}$ and mild cognitive impairment (MCI). Until now, however, rigorous studies are still lacking. To overcome the current methodological issues and to evaluate the efficacy of SGs in secondary prevention (that currently is being pursued and is considered one of the potentially attainable goals of treatment, Foster et al., 2014), the purpose of the present opinion paper is to highlight the importance of defining harmonized SGs parameters, and to propose the implementation of biomarkers as enrichment strategy and outcome measures in SGs trial design. We will now review the history and state-of-art types and use of SGs, before describing in more detail our proposal.

\section{History of Serious Games: Origin, Typologies, Target}

SGs are games designed for a primary purpose other than entertainment, enjoyment or fun (Michael and Chen, 2005). The historical origin of this oxymoron dates back to Neo-Platonists, who referred the term "serio ludere" to light-hearted approach in literature dealing with serious matters (Manning, 2004). The first use of SG oxymoron close to its current use seems to be 
in book written (Abt's, 1970), even though with a more extensive meaning. In fact, a SG could indeed be a computer game, a game, a role-playing game or even an outdoor game (Alvarez and Djaouti, 2012). The SG term in a digital context was firstly used in 2002, with the start of the Serious Game Initiative led by David Rejeski and Ben Sawyer in the US (De Gloria et al., 2014).

To date, SGs have been applied in many sectors, including education, training, defense, health, communications, marketing, politics, and the list is continually expanding (Alvarez and Djaouti, 2012). Since SGs addresses a set of markets, they are constituted by a wide variety of different types. Considering the dual nature of SGs, a system that classifies SGs according to both the "serious" and the "game" dimensions was proposed by Djaouti et al. $(2011)^{1}$. This model has classified 3080 SGs so far.

Examples of SGs include (see Alvarez and Djaouti, 2012, for a review): (i) military games, commonly dedicated to tactical and strategic training as well as recruitment for the army; (ii) edugames for educational and training purposes, also usable in a school context; (iii) advergames, where the gameplay is centered around a commercial message; (iv) newsgames that are based on current events or certain journalistic issues; (v) SGs dedicated to health sector aimed to improve player's cognitive or physical abilities; etc.

SGs do not target exclusively young gamers. A considerable proportion (20-29\%) of regular digital gamers are indeed older than 50 years (ESA, 2011; BIU, 2014). In this respect, it is worth noting the increase by $32 \%$ in the number of US females gamers aged 50 and older from 2012 to 2013 (ESA, 2014). Because the number of elderly people who play video games in the past decades has steadily increased and is predicted to grow further (Robert et al., 2014), even small beneficial effects may have significant public health implications (Alzheimer's Disease International, 2014).

\section{The State-of-Art Use of Cognitive Serious Games with Healthy Older Adults and Ad Patients}

The cognitive effect of SGs played by older adults has not yet been studied thoroughly (Weybright et al., 2010; Alzheimer's Disease International, 2014). In the context of research focused on successful cognitive aging and on the possibility to modify the cognitive decline normally associated with healthy aging (Zinke et al., 2014), anyway, SGs have been demonstrated to be a motivating tool with some beneficial effects in improving cognitive functions in healthy older adults (Nouchi et al., 2012; Anguera et al., 2013). In the study reported by Anguera et al. (2013), indeed, it's worth mentioning that: (i) SG improved both trained and untrained cognitive abilities, which is commonly referred to as a transfer effect, that is the effect due to a training not only on skills or performance that are trained, but also on skills or performance that are not trained (Nouchi et al., 2012); (ii) untrained abilities that improved were sustained attention and working memory, which are known to be involved in everyday functioning; and

${ }^{1}$ http://serious.gameclassification.com (iii) performance gains remained stable 6 months after training without booster sessions. This transfer effect of SG on the improvement of executive functions and processing speeds in the elderly has been also demonstrated with a short-term training (Nouchi et al., 2012), suggesting that a possible transfer effect from laboratory-based tasks to real world ones may be expected. Neurophysiological findings support training-induced neuroplasticity as the mechanistic basis of these SG effects (Anguera et al., 2013).

However, whether $\mathrm{AD}$ patients or population at high risk for developing $\mathrm{AD}$ (i.e., $\mathrm{MCI}$ ) may benefit from $\mathrm{SG}$ is unknown (Robert et al., 2014).

Recently, some studies have started to employ SGs with people with $\mathrm{AD}$ and MCI as a cutting-edge cognition-focused intervention (Table 1). Cognition-focused interventions fall under the broader umbrella of non-pharmacological interventions, and can be defined as interventions that directly or indirectly target cognitive functioning as opposed to interventions that focus primarily on behavioral, emotional or physical functions (BaharFuchs et al., 2013). These interventions are typically designed to promote intellectual stimulation and minimize cognitive impairment (Weybright et al., 2010). Progressive decline of cognitive functions is indeed a clinical feature of $\mathrm{AD}$ and has been found to be associated with impairment in activities of daily living (Tomaszewski Farias et al., 2009). Thus, intervention aimed at prevention and rehabilitation of such decline may promote a longer independent life at home and decrease the burden of dementia on patients and families.

Despite the promising results and the increasing interest in applying cognitive SGs to AD/MCI patients, rigorous feasibility and efficacy studies are still lacking, partly reflecting the only recent interest in employing SGs in cognitively impaired patients (Robert et al., 2014). The main methodological issues are: limitation of randomized controlled studies and lack of harmonized procedures (i.e., absence of standardized SG parameters such as when, where and with whom SGs have to be played), as well as small sample size and questionable choice of patient selection and outcome measures. However, these issues are common in studies addressing cognition-focused interventions (Woods et al., 2012; Bahar-Fuchs et al., 2013).

\section{Future Perspectives}

\section{Definition of Harmonized SGS Parameters}

To overcome the current lack of harmonized procedures, one important aspect to be taken into account in the SG trial design includes the definition of parameters such as when, where and with whom SGs are more adapted to be played by $\mathrm{AD} / \mathrm{MCI}$ patients.

According to the recommendations reported in (Robert et al., 2014), SGs for MCI patients' stimulation could be considered adapted to be used both everyday and once a week; at home, in day centers and in the nursing homes; with a therapist, a professional caregiver and a family caregiver.

In our opinion, SG trials should take into account these methodological recommendations, and assess SG feasibility and efficacy due to when, where, with whom SG is played by patients. 


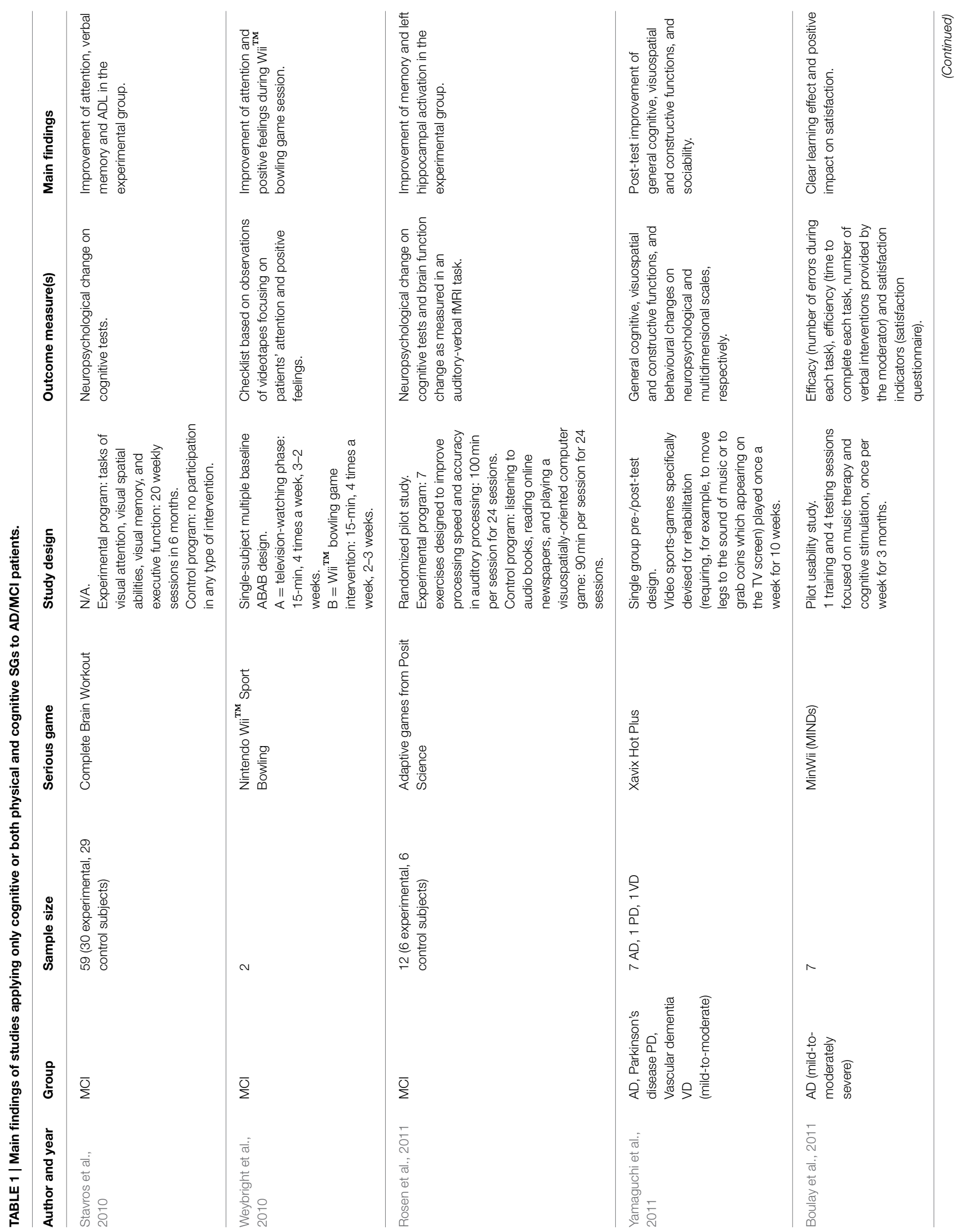




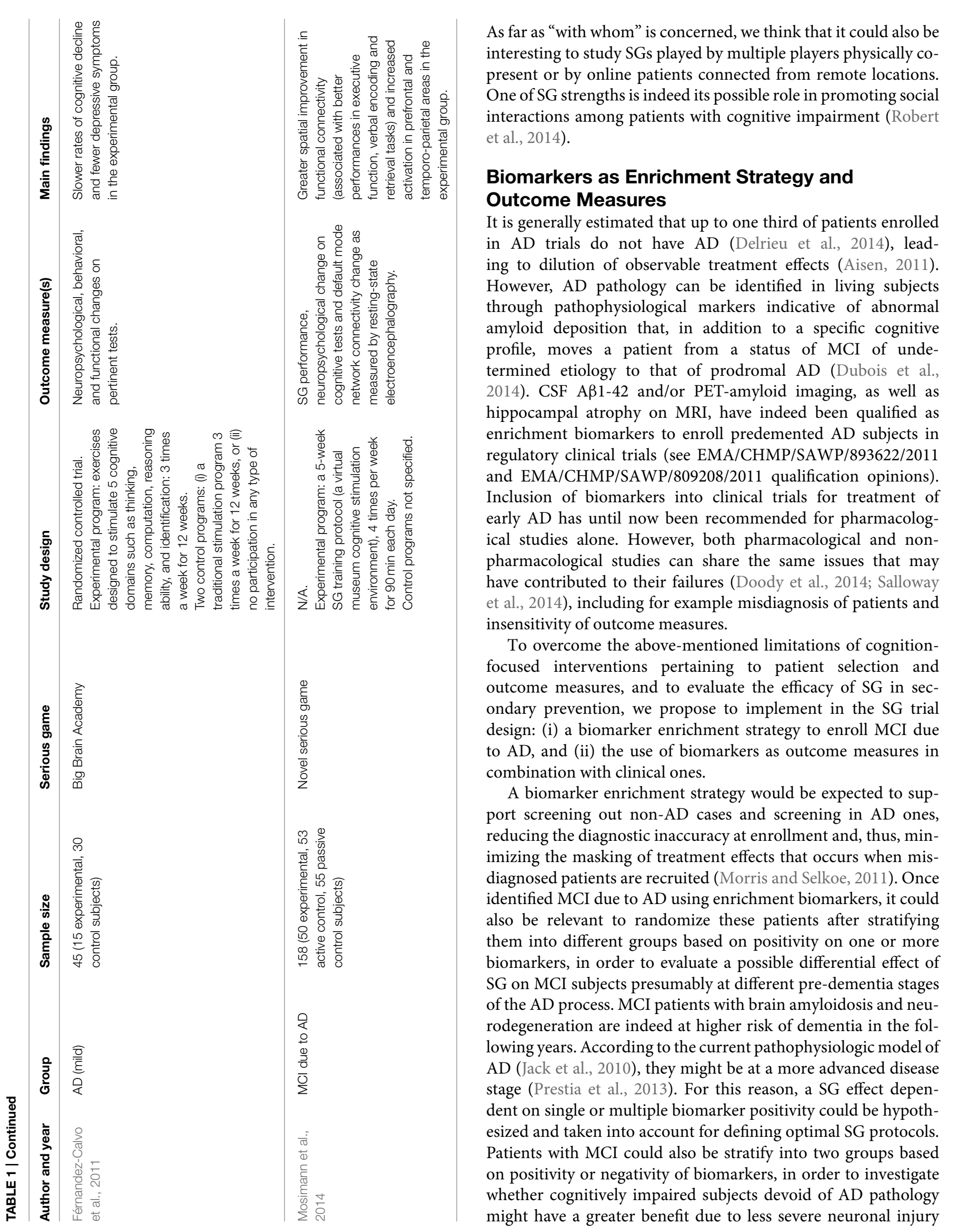


and, consequently, greater brain reserve (Stern, 2009). Finally, it could be interesting to verify if there is an association between biomarkers and methodological parameters cited in the previous subparagraph: for instance, can patients with a single positive biomarker or negativity of biomarkers take advantage from SGs played at lower time intensity (e.g., once at week) or alone at home compared with patients with multiple positive biomarkers or positivity of biomarkers, respectively?

Some studies in AD and MCI patients have shown that MRI and FDG-PET biomarkers may be more sensitive to change than clinical measures, as reported by Caroli et al. (2014) but regulatory agencies have not yet recognized biomarkers as surrogate outcome measures. This cautious approach is due to the requirement that, to be recognized as surrogate outcome measures, biomarker changes should reliably predict detectable clinical changes (Aisen, 2011). Unfortunately, the results of randomized clinical trials with anti-beta amyloid drugs (Abeta vaccine AN1792 and bapineuzumab) have until now shown no clinical efficacy despite a change in biomarkers. On the other hand, use of biomarkers would allow studies with fewer participants, shorter durations, lower costs, and with the possibility to control for the specificity of disease-modifying effect (Morris and Selkoe, 2011; Food and Drug Administration: Draft Guidance for Industry. Alzheimer's Disease: Developing Drugs for the Treatment

\section{References}

Abt, C. (1970). Serious Games. New York, NY: Viking Press.

Aisen, P. S. (2011). Clinical trial methodologies for disease-modifying therapeutic approaches. Neurobiol. Aging. 32, S64-S66. doi: 10.1016/j.neurobiolaging.2011.09.008

Alvarez, J., and Djaouti, D. (2012). Introduction au Serious Game. Paris, FR: Question Théoriques.

Alzheimer's Disease International. (2009). World Alzheimer Report 2009: The Global Prevalence of Dementia. London: Alzheimer's Disease International.

Alzheimer's Disease International. (2010). World Alzheimer Report 2010: The Global Economic Impact of Dementia. London: Alzheimer's Disease International.

Alzheimer's Disease International. (2013). Policy Brief: The Global Impact of Dementia 2013-2050. London: Alzheimer's Disease International.

Alzheimer's Disease International. (2014). World Alzheimer Report 2014: Dementia and Risk Reduction: An Analysis of Protective and Modifiable Factors. London: Alzheimer's Disease International.

Anguera, J. A., Boccanfuso, J., Rintoul, J. L., Al-Hashimi, O., Faraji, F., and Janowich, J. (2013). Video game training enhances cognitive control in older adults. Nature 501, 97-102. doi: 10.1038/nature12486

Bahar-Fuchs, A., Clare, L., and Woods, B. (2013). Cognitive training and cognitive rehabilitation for mild to moderate Alzheimer's disease and vascular dementia. Cochrane Database Syst. Rev. 6:CD003260. doi: 10.1002/14651858.CD003260

Ballard, C., Gauthier, S., Corbett, A., Brayne, C., Aarsland, D., and Jones, E. (2011). Alzheimer's disease. Lancet 377, 1019-1031. doi: 10.1016/S01406736(10)61349-9

BIU. (2014). Gamer-Statistiken. Available online at: http://www.biu-online. de/en/facts/market-figures-2013/gamer-statistics/age-distribution.html

Boulay, M., Benveniste, S., Boespug, S., Jouvelot, P., and Rigaud, A. S. (2011). A pilot usability study of MINWii, a music therapy game for demented patients. Technol. Health Care 19, 233-246. doi: 10.3233/THC-2011-0628

Caroli, A., Prestia, A., Wade, S., Chen, K., Ayutyanont, N., and Landau, S. M. (2014). Alzheimer disease biomarkers as outcome measures for clinical trials in MCI. Alzheimer Dis. Assoc. Disord. doi: 10.1097/WAD.0000000000000071. [Epub ahead of print]. of Early Stage Disease, 2013). Recent non-pharmacological studies that have incorporated hippocampal atrophy as biomarker outcome have found a disease-modifying benefit of aerobic exercise in early AD over 6 months (Honea et al., 2014), suggesting that similar results could also be found applying physical and cognitive SGs.

\section{Conclusions}

If the presumed beneficial effects of SGs will be demonstrated by robust studies, the potential societal impact will be huge considering the very high prevalence of cognitive impairment due to $\mathrm{AD}$, the popularity of video games played by baby-boomers now at risk of dementia, the current lack of effective treatments, and the cost-effectiveness of these enjoyable interventions. Moreover, video games already marketed to older adults for maintaining cognitive health may be seen as a scale up of a prevention program in a high-risk subgroup of the population (Alzheimer's Disease International, 2014). SGs may represent a motivating, low-barrier, engaging and sustainable method to improve or at least delay the decline in specific social, sensory-motor, cognitive and emotional functions of elderly people (Wiemeyer and Kliem, 2012).

De Gloria, A., Bellotti, F., Berta, R., and Lavagnino, E. (2014). Serious Games for education and training. Int. J. Serious Game 1, 1.

Delrieu, J., Ousset, P. J., Voisin, T., and Vellas, B. (2014). Amyloid beta peptide immunotherapy in Alzheimer disease. Rev. Neurol. 170, 739-748. doi: 10.1016/j.neurol.2014.10.003

Djaouti, D., Alvarez, J., and Jessel, J. P. (2011). "Classifying serious games: the G/P/S model," in Handbook of Research on Improving Learning and Motivation through Educational Games: Multidisciplinary Approaches, ed P. Felicia (Hershey, PA: IGI Global), 118-136.

Doody, R. S., Thomas, R. G., Farlow, M., Iwatsubo, T., Vellas, B., and Joffe, S. (2014). Phase 3 trials of solanezumab for mild-to-moderate Alzheimer's disease. N. Engl. J. Med. 370, 311-321. doi: 10.1056/NEJMoa 1312889

Dubois, B., Feldman, H. H., Jacova, C., Hampel, H., Molinuevo, J. L., and Blennow, K. (2014). Advancing research diagnostic criteria for Alzheimer's disease: the IWG-2 criteria. Lancet Neurol. 13, 614-629. doi: 10.1016/S14744422(14)70090-0

ESA. (2011). Essential Facts About the Computer and Video Games Industry. Available online at: http://www.isfe.eu/sites/isfe.eu/files/attachments/ esa_ef_2011.pdf

ESA. (2014). Essential Facts About the Computer and Video Games Industry. Available online at: http://www.isfe.eu/sites/isfe.eu/files/attachments/ esa_ef_2014.pdf

Férnandez-Calvo, B., Rodriguez-Pérez, R., Contador, I., Rubio-Santorum, A., and Ramos, F. (2011). Efficacy of cognitive training programs based on new software technologies in patients with Alzheimer-type dementia. Psicothema 23, 44-50.

Food and Drug Administration: Draft Guidance for Industry. Alzheimer's Disease: Developing Drugs for the Treatment of Early Stage Disease. (2013). Available online at: http://www.fda.gov/downloads/ Drugs/GuidanceComplianceRegulatoryInformation/Guidances/UCM338287. pdf. (Accessed: February 24, 2013).

Foster, N. L., Hackett, J. S., White, G., Chenevert, S., Svarvar, P., and Bain, L. (2014). Justifying reimbursement for Alzheimer's diagnostics and treatments: seeking alignment on evidence. Alzheimers Dement. 10, 503-508. doi: 10.1016/j.jalz.2014.05.003 
Honea, R., Vidoni, E. D., Morris, J., Graves, R., Perea, R. D., and Van Sciver, A. (2014). Aerobic exercise reduces hippocampal atrophy in individuals with early Alzheimer's disease. Alzheimer's Dement. 10, P303. doi: 10.1016/j.jalz.2014.04.509

Jack, C. R. Jr., Knopman, D. S., Jagust, W. J., Shaw, L. M., Aisen, P. S., and Weiner, M. W. (2010). Hypothetical model of dynamic biomarkers of the Alzheimer's pathological cascade. Lancet Neurol. 9, 119-128. doi: 10.1016/S1474-4422(09)70299-6

Manning, J. (2004). The Emblem. London, UK: Reaktion Books.

Michael, D., and Chen, S. (2005). Serious Games: Games that Educate, Train and Inform. Boston, MA: Thomson Course Technology PTR Development.

Morris, J. C., and Selkoe, D. J., (2011). Recommendations for the incorporation of biomarkers into Alzheimer clinical trials: an overview. Neurobiol Aging. 1, S1-S3. doi: 10.1016/j.neurobiolaging.2011.09.005

Mosimann, U., Tarnanas, I., Dimitriadis, S., Laskaris, N., Bamidis, P., and Tsolaki, M. (2014). Serious gaming enhances cognitive function in MCI due to Alzheimer's disease. Alzheimer's Dementia 10, P922. doi: 10.1016/j.jalz.2014.07.135

Nouchi, R., Taki, Y., Takeuchi, H., Hashizume, H., Akitsuki, Y., and Shigemune, Y. (2012). Brain training game improves executive functions and processing speed in the elderly: a randomized controlled trial. PLOS ONE 7:e29676. doi: 10.1371/journal.pone.0029676

Prestia, A., Caroli, A., van der Flier, W. M., Ossenkoppele, R., Van Berckel, B., and Barkhof, F. (2013). Prediction of dementia in MCI patients based on core diagnostic markers for Alzheimer disease. Neurology 80, 1048-1056. doi: 10.1212/WNL.0b013e3182872830

Robert, P. H., König, A., Amieva, H., Andrieu, S., Bremond, F., and Bullock, R. (2014). Recommendations for the use of Serious Games in people with Alzheimer's Disease, related disorders and frailty. Front. Aging Neurosci. 6:54. doi: 10.3389/fnagi.2014.00054

Rosen, A. C., Sugiura, L., Kramer, J. H., Whiteld-Gabrieli, S., and Gabrieli, J. D. (2011). Cognitive training changes hippocampal function in mild cognitive impairment: a pilot study. J. Alzheimers Dis. 26, 349-357. doi: 10.3233/JAD2011-0009

Salloway, S., Sperling, R., Fox, N. C., Blennow, K., Klunk, W., and Raskind, M. (2014). Two phase 3 trials of bapineuzumab in mild-to-moderate Alzheimer's disease. N. Engl. J. Med. 23, 322-333. doi: 10.1056/NEJMoa 1304839

Stavros, Z., Fotini, K., and Magda, T. (2010). "Computer based cognitive training for patients with mild cognitive impairment (mci)," in Proceedings of the 3rd International Conference on Pervasive Technologies Related to Assistive Environments, PETRA'10 (Petras, RI: ACM), 1-3.
Stern, Y. (2009). Cognitive reserve. Neuropsychologia 47, 2015-2028. doi: 10.1016/j.neuropsychologia.2009.03.004

Tarnanas, I., Tsolaki, M., Nef, T., M., Müri, R., and Mosimann, U. P. (2014). Can a novel computerized cognitive screening test provide additional information for early detection of Alzheimer's disease? Alzheimers Dement. 10, 790-798. doi: 10.1016/j.jalz.2014.01.002

Tomaszewski Farias, S., Cahn-Weiner, D. A., Harvey, D. J., Reed, B. R., Mungas, D., and Kramer, J. H. (2009). Longitudinal changes in memory and executive functioning are associated with longitudinal change in instrumental activities of daily living in older adults. Clin. Neuropsychol. 23, 446-461. doi: 10.1080/13854040802360558

Wan Shamsuddin, S. N., Valerie, L., and Hassan, U. (2011). Virtual environment design guidelines for elderly people in early detection of dementia. World Acad. Sci. Eng. Technol. 5, 1860-1864.

Weybright, E., Dattilo, J., and Rusch, F. (2010). Effects of an interactive video game (Nintendo Wii) on older women with mild cognitive impairment. Ther. Recreation J. 44, 271-287.

Wiemeyer, J., and Kliem, A. (2012). Serious games in prevention and rehabilitation - a new panacea for elderly people? Eur. Rev. Aging Phys. Activ. 9, 41-50. doi: 10.1007/s11556-011-0093-x

Woods, B., Aguirre, E., Spector, A. E., and Orrell, M. (2012). Cognitive stimulation to improve cognitive functioning in people with dementia. Cochrane Database Syst. Rev. 2:CD005562. doi: 10.1002/14651858. CD005562

Yamaguchi, H., Maki, Y., and Takahashi, K. (2011). Rehabilitation for dementia using enjoyable video-sports games. Int. Psychogeriatr. 23, 674-676. doi: 10.1017/S1041610210001912

Zinke, K., Zeintl, M., Rose, N. S., Putzmann, J., Pydde, A., and Kliegel, M. (2014). Working memory training and transfer in older adults: effects of age, baseline performance, and training gains. Dev. Psychol. 50, 304-315. doi: $10.1037 / \mathrm{a} 0032982$

Conflict of Interest Statement: The authors declare that the research was conducted in the absence of any commercial or financial relationships that could be construed as a potential conflict of interest.

Copyright (C) 2015 Muscio, Tiraboschi, Guerra, Defanti and Frisoni. This is an openaccess article distributed under the terms of the Creative Commons Attribution License (CC BY). The use, distribution or reproduction in other forums is permitted provided the original author(s) or licensor are credited and that the original publication in this journal is cited, in accordance with accepted academic practice. No use, distribution or reproduction is permitted which does not comply with these terms. 